\title{
ASSESSING THE RELATION BETWEEN COVID-19 PERCEPTION AND ACCEPTANCE OF THE COVID-19 VACCINE IN KENYA.
}

\author{
AUTHOR: Eva W. Kivuva-Student Kenyatta University-Kenya \\ https://orcid.org/0000-0003-4035-261X
}

Corresponding Author: Eva W. Kivuva

ADRESS: 129-90125 Kikima Mbooni

TEL: 254-700643937

EMAIL:kivuvaeva18@students.ku.ac.ke

ALT EMAIL: evawavinya@gmail.com

\section{KEYWORDS}

Covid-19

Covid-19 perception

Covid-19 vaccine

Covid-19 vaccine acceptance

Information dispensation 


\section{ABSTRACT \\ PURPOSE}

Since the start of the Covid-19 pandemic in 2019 in China and its spread, it continues to terrorize the Kenyan population with new infections and death cases daily. This study was done to determine if the perception of the disease influenced vaccine acceptance within the Kenyan population.

\section{METHODS}

Electronically shared questionnaires were used to conduct this survey in the Kenyan adult population in January and February 2021 due to Covid-19 restrictions, to evaluate the Kenyan populations' Covid-19 perception and relation to Covid-19 vaccine acceptance rate. One-way ANOVA was performed to check whether the perception of respondents and acceptance of the vaccine differed significantly and correlation was done to evaluate the relationship between the perception and vaccine acceptance.

\section{RESULTS}

Out of total sum of 659 participants, 451(68\%) perceived the existence of Covid-19 in the country; 338 (75\%) were willing to take the vaccine if it was made available to them. Noticeable differences between the perception and acceptance rate of the vaccine across different demographic characteristics.

\section{CONCLUSION}

Covid-19 perception strongly relates to the acceptance of the vaccine in the Kenyan population.

\section{ABBREVIATIONS}

ANOVA- Analysis of variance 


\section{INTRODUCTION}

After the break out of the Covid-19 in Wuhan, China in December 2019(Velavan \& Meyer, 2020) and its spread globally since, the Covid-19 vaccine has been long awaited. The outbreak started in Hubei province(Gondouin, 2020; Velavan \& Meyer, 2020) and quickly spread across the globe affecting the worlds "normal” way of life. The virus was classified as a world pandemic owing to its quick spread across the globe and high mortality rate (Sohrabi et al., 2020; WHO Covid-19, 2020). WHO suggested different measures to help countries curb and slow the spread of the virus like; wearing of mask, social distancing, and countries ban travel and even closed their borders. However this could only control the spread while a fast and true remedy was awaited upon. The number of Covid-19 cases currently across the globe and in Kenya(Odhiambo et al., 2020), only and the numbers keep increasing every day(Brand et al., 2020; Mbae, 2020; Odhiambo et al., 2020). The mortality rate to this day across the globe lie at 3.34 million as of May 14, 2021 with 2968 in Kenya( Google Search, May 2021). Many large pharmaceuticals have being working on the Covid-19 vaccine and on December 2020 the first vaccines to the virus were fist announced to be ready for roll out to the populations(WHO Covid19, 2020). Big pharmaceuticals like Moderna, Pfizer announced their first vaccines in a record time of less than a year of formulation trials and testing, the vaccines which had taken incredibly less time as compared to major vaccines(Larson et al., 2014a).

Vaccine acceptance by a population is determined by factors like education(Goldstein et al., 2015), various social (Larson et al., 2014b, 2015; Ni et al., 2021)factors and its performance(MacDonald et al., 2015; Ni et al., 2021). The perception of the disease is one of the 
major factors which determine if people are willing to take vaccine of not. This study aims to evaluate the perception and acceptance of the Covid-19 vaccine in Kenya as the government intends to start immunizing people in 2021. The assessment of the perception and acceptance of the vaccine will help direct the ministry of health in Kenya in sensitization strategies concerning the vaccines and the clarification of myths and misconceptions surrounding the vaccine and the virus.

\section{MATERIALS AND METHODS}

Data were collected using electronic questionnaire developed via survey monkey; a platform in which one can develop and conduct surveys freely, and widely shared via whatsapp emails and Facebook in January and February 2021. Sampling aimed at a true representation of the Kenyan population with different genders and age groups, education level, residence and employment status represented. The eligibility of the respondents was based on being18 years and above, have access to a smart phone or computer and the internet. Participation to take the survey was purely voluntary and no participants were forced or compensated to give the information provided to take this study. Consent for the information provided was required in first page before proceeding with the survey. The survey was divided to two sections; section one on consent, and personal details; basic demographic characteristic details like, age, employment status, county of residence in Kenya, education level and gender. Consent was required to proceed with the survey and a pledge for honesty in the answering the survey questions. The survey then proceeded to ask if the respondent believed that Covid-19 is real, this was put on a scale of 0 to 1 with 0 =strongly disagree, $1=$ strongly agree and a section was added for an option of undecided or not sure. The next question proceeded to ask the respondents that if the Covid-19 vaccine was made available to them would they take it, the responses were again put on a scale 
of 0 to1 with 0 been strongly disagree, 1 = strongly agree and a third section of the undecided. Lastly the respondents were required to give their confidence level in the government provided Covid-19 vaccine on a scale of 0-10,0 not at all confident 5 was averagely confident and 10 was fully confident the higher the number in the scale the higher the participants confidence in the government provided vaccine. The respondents were given the assurance that their personal details would not be shared and privacy will be maintained.

Onset descriptive statistics were used to analyze the data collected; percentages of all the demographic characteristics were calculated and tabulated, the age, gender, resident county, education level and employment status. One-way ANOVA was performed to determine if the

means of perception and vaccine acceptance differed significantly and correlation was performed to further determine the relationship between perception and vaccine acceptance in the population. Association of the Covid-19 vaccine acceptance percentage and Covid-19 perception was charted against different demographic characteristics and assessed against those characteristics.

\section{RESULTS}

The survey was open to any participant willing and eligible to fill out; 772 surveys were filled, out of which 659(85\%) were complete and those were used to conduct the analysis and present the hereby drawn conclusions and recommendations. Table 1 presents the different demographic characteristics across all the participants, 453(69\%) participants were female while 206(31\%) were male. A high number of the participants were below the age of 35 years distributed among; $16 \%$ at the age between 18 and24 years, (40\%) were between the age of 25 and 34 years and 
$23 \%$ were between the ages of 34 to 44 years of age. The rest (20\%) were above the age of 45 years. In the list of respondents the data was presented using the old province partition of Kenya and among the 8 provinces; 7 provinces were represented in the survey, most of the participants ( $n=524,80 \%$ ) were between 18 years, and most were from Nairobi province $(n=268,41 \%)$. A high percentage of the participants had a high school education and above $(\mathrm{n}=500,87 \%)$ and a high number of the participants were ever employed $(n=261,40 \%)$ or unemployed ( $n=245$, $37 \%)$.

Of the 659 participants, 451 perceived existence of Covid-19. The perception differed across demographic characteristics with 106(51\%) males and 345(76\%) females accepting that Covid19 was real. Of the 451 participants that perceived that Covid-19 was real the highest number was between the age of 25 years and 34 years ( $n=169,37 \%)$. Most were either residing in Nairobi province or in Central province in Kenya? A high percentage of the participants that agreed that Covid-19 was real, most had a high school education level and above; 415(92\%) and most were either unemployed ( $\mathrm{n}=184,40 \%)$ or employed ( $\mathrm{n}=145,32 \%)$. Table1; fig1 and fig 2.

One way ANOVA (Table2) carried out on the obtained data showed a significant difference ( $f>f$ critical) between the mean population of respondents' on the perception and vaccine acceptance. Correlation performed (figure3) to evaluate the relation between Covid-19 perception and the vaccine acceptance showed the two variances strongly correlated (0.92). The Covid-19 vaccine acceptance also differed across all demographic characteristics across the 659 participants; as showed in fig1 and fig3. Only 424(64\%) said they would accept the vaccine if it was recommended to them. This compared to the number of participants that perceived the existence of Covid-19 was lower by $46 \%$; fig1. Fifty percent more females said that if the vaccine was made available to them compared to male participants. A higher percentage of employed 
participants said if the Covid-19vaccine was recommended to them, they would accept it compared to the unemployed. The rate of Covid-19 vaccine acceptance showed a close relation to the perception of Covid-19 existence. 184 unemployed participants perceived the existence of Covid-19 but only 75 participants said they would take the vaccine. An interesting demographic difference is that; participants living in provinces considered rural which not Nairobi, Central are or Coast had a low perception of Covid-19 existence, but the high number of the participants say that they would take the vaccine if it was made available compared to people living in urban areas which are current hot zones for Covid-19. 401, of the 659 participants reported no confidence in the government or the vaccine.

\section{DISCUSSION}

With the first batch of vaccine having arrived in country in March, the number of civilians that have accepted or taken the vaccine is considerably low. To meet the herd immunity threshold(Randolph \& Barreiro, 2020), a high percentage of the population has to be immune to the virus. The government needs to increase sensitization of the population to create awareness and build confidence in the vaccine. The health ministry in the national government and county level need to create strategies for the population to be informed and educated about the virus and the vaccine as the disease perception is linear to vaccine acceptance.

Due to Covid-19 restrictions the survey was done online hence fast distribution of the questionnaire, and access to remote areas which would not be accessible otherwise. The survey however was limited to people who had access to a smartphone or a computer and had internet

access. This highly limited the survey to urban areas mostly and not enough in remote areas. The 
survey could only be done by English understanding individuals however this was solved by encouraging assistance to translate the survey.

The survey was done for two months in 2021 while the Kenyan population was at 54 Million constituting of around 25M adults(World meter, 2015). The number of participants of this survey were 772 adults above 18 years and older. Of the 772 filled surveys, 659 were complete and the rest were considered ruined. Of the 659 respondents 453(69\%) were female and 206 (31\%) were male. Majority of the respondents were below the age of 45 and 20\% were 45 years and above. The highest number of participants were from the city; Nairobi province and central province. The number of participants willing to take the vaccine are 424 (64\%) while this is above average, the need to build more confidence among Kenyans is a necessity.

Since the beginning of Covid-19 in China and its arrival in Kenya in February 2020(Brand et al., 2020; N., 2020) the number of infection and deaths have being heavily distributed within major cities and towns in the country, with a high percentage in the country's city; Nairobi. With the collected demographic characteristics Covid-19 vaccine acceptance can be visualized and maybe predicted to a certain level. However the perception of the existence of the disease is of importance to the reception and acceptance of the vaccine by the Kenyan population and this can be dictated and predicated with a high accuracy with the available demographics(Larson et al., 2014a). Most of the young, unemployed, with a lower education population largely see that there is no Covid-19 in the country and perceive it as a scam to tap money by government officials. The current scandals surrounding large government contractors in the health industry in this period has not helped the case. The perception level therefore differed not only based on education level, employment status but also based on residence area of the population. As people living in places considered to be rural in the country had a low perception of the disease hence a 
low acceptance of the vaccine. In addition as education level increased it translated to higher perception of the disease and therefore higher acceptance rate in Covid-19 vaccine. Also as the education level increased chances of unemployment decreases and this also was reported to change the perception of Covid-19 and therefore the acceptance of the Covid-19 vaccine. In sequence higher education level meant high chances employment therefore increased income and this also changed the perception of Covid-19 which was directly related to the acceptance of the Covid-19 vaccine. However a high rate of Covid-19 disease perception does not actually mean a high rate in the acceptance of the vaccine. A percentage of the population that agreed that the disease was real still did not accept the vaccine due to several factors like, but not limited to, mistrust in the health system, mistrust in a foreign vaccine. The population that mistrusted the vaccine being foreign with the scare that African countries were being used as guinea pig to test on. And while reported perception does not mean Covid-19 vaccine acceptance; acceptance does not mean actual intent to take the vaccine if presented especially basing on the acceptance level since the arrival of the vaccine in the country in March 2021. 


\section{CONCLUSION}

This study will help the national and county government to develop and strategize sensitization especially in most vulnerable groups effectively. This proves the intersectionality between continued corruptions, current scandals surrounding government contracted health wings in the ministry of health in the national government can be linked to the Kenyan population low trust level in the healthcare ministry. This can be especially reported among the youths especially the unemployed percentage which is a larger percentage. In return it explains the differences in the health choices from the population. A large percentage that do not perceive the virus to be existent in the country do not accept the vaccine majorly youths. This raises a disparity because according to statistics the high number of infections is among the older population an also the percentage of deaths and infections and deaths only seems to be concentrated in the cities like Nairobi and Mombasa city which leads to the larger population not believing in the existence of the virus as they never see any cases close to home. With this report low to no cases in rural areas in the country led to rejection that Covid-19 is real which translates to rejection of the covid-19 vaccine.

Since the start of Covid-19 in China, and its first infection in Kenya in February 2020 the news networks have continued to air its progress; new infection and deaths daily. However none of the networks have displayed the performance of the vaccine since its arrival in the country and this is not a confidence builder among Kenyans.

Based on this study the factors that affect the acceptance of Covid-19 vaccine are; the perception of the Covid-19 virus, the coverage of the infections, deaths and vaccine acceptance and performance by media in the country. The health ministry needs to invest in building confidence of the Kenyan population in the vaccine for the acceptance level to raise, so as to achieve herd 
immunity. The government needs to educate the population on the vaccine with descriptive pharmacological explanations through media and control any misinformation about the disease or the vaccine. This need to be done especially in high risk persons, the youth and in rural areas. The data in this study shows that a low percentage of the participants (33\%) across the counties would accept the covid-19 vaccine if it were made available to them. To achieve herd immunity a significant number(Randolph \& Barreiro, 2020) of the population need to be immune and in this case vaccinated. This is study is to enable the Kenyan government to do sensitization and countrywide awareness to best educate the population on Covid-19 and the Covid-19 vaccine especially the most vulnerable and marginalized groups.

\section{Ethics and other permissions:}

The data presented required the participants to agree to the terms and conditions before proceeding to take the survey, those that did not agree could not proceed to take the survey.

\section{Funding:}

This study was individual research study and was not funded by any organization hence no bias was present in doing the study or presenting the above results.

\section{Conflict of interests}

No known conflict of interests.

\section{Data availability statement:}

The raw data will be accessible on contacting the corresponding author. 



\section{REFERENCES}

Brand, S. P. C., Aziza, R., Kombe, I. K., Agoti, C. N., Hilton, J., Rock, K. S., Parisi, A., Nokes, D. J., Keeling, M. J., \& Barasa, E. W. (2020). Forecasting the scale of the COVID-19 epidemic in Kenya. In medRxiv. https://doi.org/10.1101/2020.04.09.20059865

Goldstein, S., MacDonald, N. E., Guirguis, S., Eskola, J., Liang, X., Chaudhuri, M., Dube, E., Gellin, B., Larson, H., Manzo, M. L., Reingold, A., Tshering, K., Zhou, Y., Duclos, P., Hickler, B., \& Schuster, M. (2015). Health communication and vaccine hesitancy. Vaccine, 33(34), 4212-4214. https://doi.org/10.1016/j.vaccine.2015.04.042

Gondouin, B. (2020). COVID-19. Nephrologie et Therapeutique. https://doi.org/10.1016/S17697255(20)30419-3

how many covid cases in the world now - Google Search. (n.d.). Retrieved March 30, 2021, from https://www.google.com/search?

$\mathrm{q}=$ how + many+covid+cases+in+the+world+now\&rlz=1C1EJFC_enKE868KE868\&oq=how

+ many + covid+cases + in + the+world + now $\&$ aqs $=$ chrome. .69i57j0l9.23085j0j7\&sourceid=chr ome\&ie=UTF-8

Larson, H. J., Jarrett, C., Eckersberger, E., Smith, D. M. D., \& Paterson, P. (2014a). Understanding vaccine hesitancy around vaccines and vaccination from a global perspective: A systematic review of published literature, 2007-2012. In Vaccine. https://doi.org/10.1016/j.vaccine.2014.01.081

Larson, H. J., Jarrett, C., Eckersberger, E., Smith, D. M. D., \& Paterson, P. (2014b). Understanding vaccine hesitancy around vaccines and vaccination from a global perspective: A systematic review of published literature, 2007-2012. In Vaccine (Vol. 32, 
Issue 19, pp. 2150-2159). Elsevier BV. https://doi.org/10.1016/j.vaccine.2014.01.081

Larson, H. J., Jarrett, C., Schulz, W. S., Chaudhuri, M., Zhou, Y., Dube, E., Schuster, M., MacDonald, N. E., Wilson, R., Eskola, J., Liang, X., Gellin, B., Goldstein, S., Larson, H., Manzo, M. L., Reingold, A., Tshering, K., Duclos, P., Guirguis, S., \& Hickler, B. (2015). Measuring vaccine hesitancy: The development of a survey tool. Vaccine, 33(34), 41654175. https://doi.org/10.1016/j.vaccine.2015.04.037

MacDonald, N. E., Eskola, J., Liang, X., Chaudhuri, M., Dube, E., Gellin, B., Goldstein, S., Larson, H., Manzo, M. L., Reingold, A., Tshering, K., Zhou, Y., Duclos, P., Guirguis, S., Hickler, B., \& Schuster, M. (2015). Vaccine hesitancy: Definition, scope and determinants. Vaccine, 33(34), 4161-4164. https://doi.org/10.1016/j.vaccine.2015.04.036

Mbae, N. (2020). COVID-19 in Kenya. Electronic Journal of General Medicine, 17(6). https://doi.org/10.29333/ejgm/7896

N., M. (2020). COVID-19 in Kenya. Electronic Journal of General Medicine, 17(6).

Ni, L., Chen, Y. wang, \& de Brujin, O. (2021). Towards understanding socially influenced vaccination decision making: An integrated model of multiple criteria belief modelling and social network analysis. European Journal of Operational Research, 293(1), 276-289. https://doi.org/10.1016/j.ejor.2020.12.011

Odhiambo, J. O., Ngare, P., Weke, P., \& Otieno, R. O. (2020). Modelling of COVID-19 Transmission in Kenya Using Compound Poisson Regression Model. Journal of Advances in Mathematics and Computer Science. https://doi.org/10.9734/jamcs/2020/v35i230252

Randolph, H. E., \& Barreiro, L. B. (2020). Herd Immunity: Understanding COVID-19. In Immunity (Vol. 52, Issue 5, pp. 737-741). Cell Press.

https://doi.org/10.1016/j.immuni.2020.04.012

Sohrabi, C., Alsafi, Z., O’Neill, N., Khan, M., Kerwan, A., Al-Jabir, A., Iosifidis, C., \& Agha, R. (2020). World Health Organization declares global emergency: A review of the 2019 novel coronavirus (COVID-19). In International Journal of Surgery. https://doi.org/10.1016/j.ijsu.2020.02.034

Velavan, T. P., \& Meyer, C. G. (2020). The COVID-19 epidemic. In Tropical Medicine and 
International Health. https://doi.org/10.1111/tmi.13383

WHO Covid-19. (2020). Draft landscape of COVID-19 candidate vaccines. Who.

Worldmeter. (2015). Current World Population. In World population. 


\section{TABLES}

\section{Table1}

Perception of Covid-19 existence Covid-19 vaccine acceptance and confidence in government provided vaccine across all demographic characteristics between January and $28^{\text {th }}$ February 2021 in Kenya.

\begin{tabular}{|c|c|c|c|c|c|c|c|}
\hline \multirow[b]{2}{*}{ gender } & \multirow[t]{2}{*}{ total $\mathrm{N}=659$} & \multirow[t]{2}{*}{ totaln $(\%)$} & \multicolumn{2}{|c|}{ perceptionof covid 19 e perception percetage } & \multirow[t]{2}{*}{ covid 19 vaccince acce } & \multicolumn{2}{|c|}{ covid19 vaccineaccept: Confidence in govt } \\
\hline & & & & & & & \\
\hline male & 206 & $31.26 \%$ & 106 & $51.46 \%$ & 115 & $55.83 \%$ & 109 \\
\hline female & 453 & $68.74 \%$ & 345 & $76.16 \%$ & 309 & $68.21 \%$ & 292 \\
\hline others & 0 & & 451 & & 424 & & 401 \\
\hline sum & 659 & & & & & & \\
\hline \multicolumn{8}{|l|}{ age } \\
\hline $18-24$ & 106 & $16.08 \%$ & 81 & $76.42 \%$ & 51 & $48.11 \%$ & 27 \\
\hline $25-34$ & 263 & $39.91 \%$ & 169 & $64.26 \%$ & 107 & $40.68 \%$ & 54 \\
\hline $35-44$ & 155 & $23.52 \%$ & 89 & $57.42 \%$ & 146 & $94.19 \%$ & 156 \\
\hline $45-54$ & 90 & $13.66 \%$ & 79 & $87.78 \%$ & 82 & $91.11 \%$ & 98 \\
\hline \multirow[t]{2}{*}{ 55above } & 45 & $6.83 \%$ & 33 & $73.33 \%$ & 38 & $84.44 \%$ & 66 \\
\hline & 659 & & & & & & \\
\hline \multicolumn{8}{|l|}{ redident province } \\
\hline eastern & 157 & $23.82 \%$ & 67 & $42.68 \%$ & 150 & $96 \%$ & 115 \\
\hline western & 35 & $5.31 \%$ & 29 & $82.86 \%$ & 17 & $49 \%$ & 7 \\
\hline nairobi & 268 & $40.67 \%$ & 224 & $83.58 \%$ & 156 & $58 \%$ & 200 \\
\hline central & 175 & $26.56 \%$ & 119 & $68.00 \%$ & 89 & $51 \%$ & 69 \\
\hline rift valley & 5 & $0.76 \%$ & 5 & $100.00 \%$ & 1 & $20 \%$ & 1 \\
\hline coast & 4 & $0.61 \%$ & 1 & $25.00 \%$ & 0 & $0 \%$ & 0 \\
\hline \multirow[t]{2}{*}{ nyanza } & 15 & $2.28 \%$ & 6 & $40.00 \%$ & 11 & $73 \%$ & 9 \\
\hline & 659 & & & & & & \\
\hline \multicolumn{8}{|l|}{ education level } \\
\hline no highschool & 72 & $10.93 \%$ & 36 & $50.00 \%$ & 28 & $39 \%$ & 9 \\
\hline highscholl/technical & 215 & $32.63 \%$ & 111 & $51.63 \%$ & 102 & $47 \%$ & 133 \\
\hline college & 237 & $35.96 \%$ & 171 & $72.15 \%$ & 187 & $79 \%$ & 161 \\
\hline \multirow[t]{2}{*}{ graduate } & 135 & $20.49 \%$ & 133 & $98.52 \%$ & 107 & $79 \%$ & 98 \\
\hline & 659 & & & & & & \\
\hline \multicolumn{8}{|l|}{ employment status } \\
\hline unemployed & 245 & $37.18 \%$ & 184 & $75.10 \%$ & 75 & $31 \%$ & 38 \\
\hline employed & 261 & $39.61 \%$ & 145 & $55.56 \%$ & 215 & $82 \%$ & 151 \\
\hline self emplyed & 67 & $10.17 \%$ & 45 & $67.16 \%$ & 55 & $82 \%$ & 53 \\
\hline \multirow[t]{2}{*}{ retired } & 86 & $13.05 \%$ & 77 & $89.53 \%$ & 79 & $92 \%$ & 61 \\
\hline & 659 & & & & & & \\
\hline
\end{tabular}




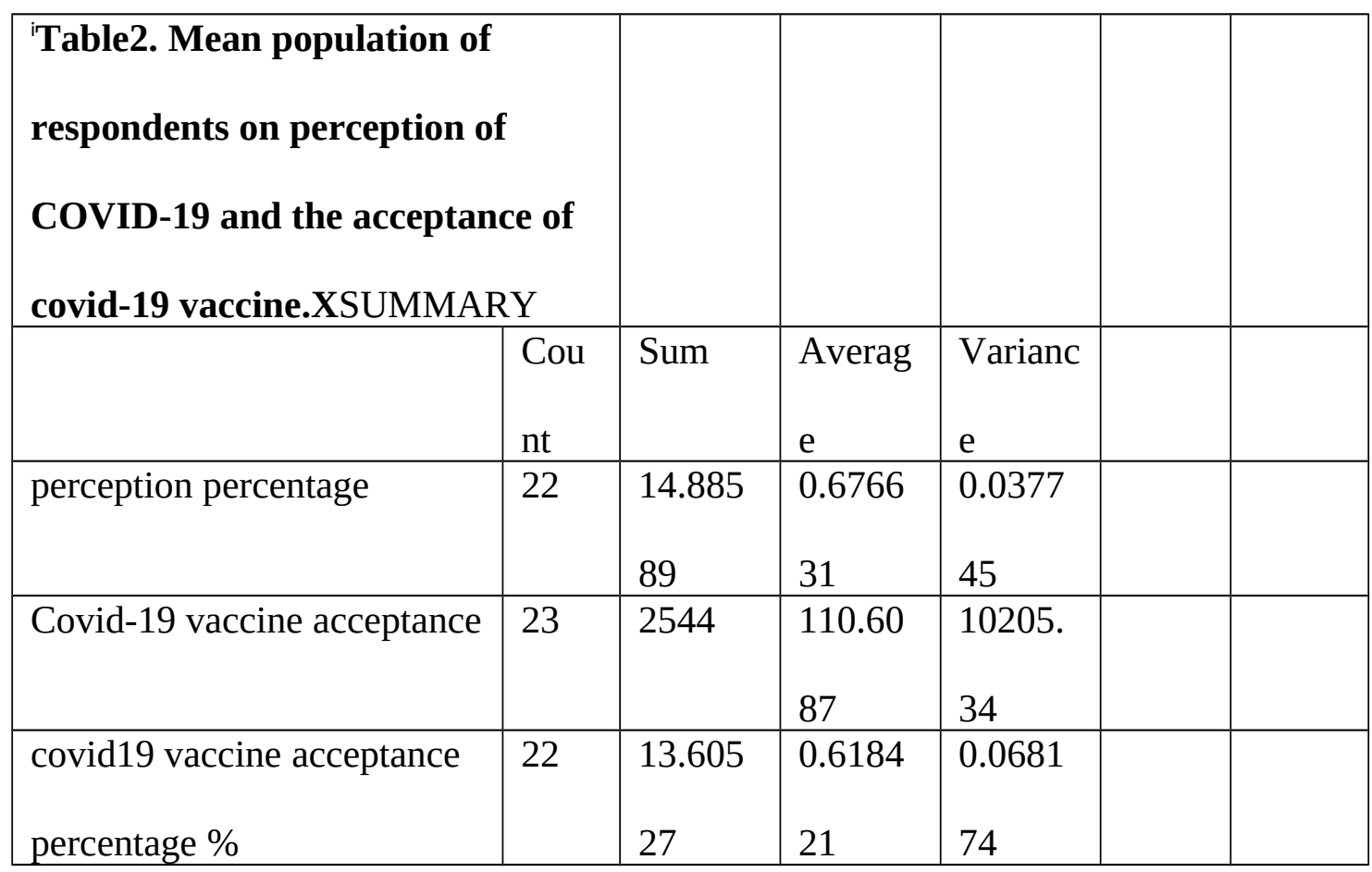




\section{FIGURES}

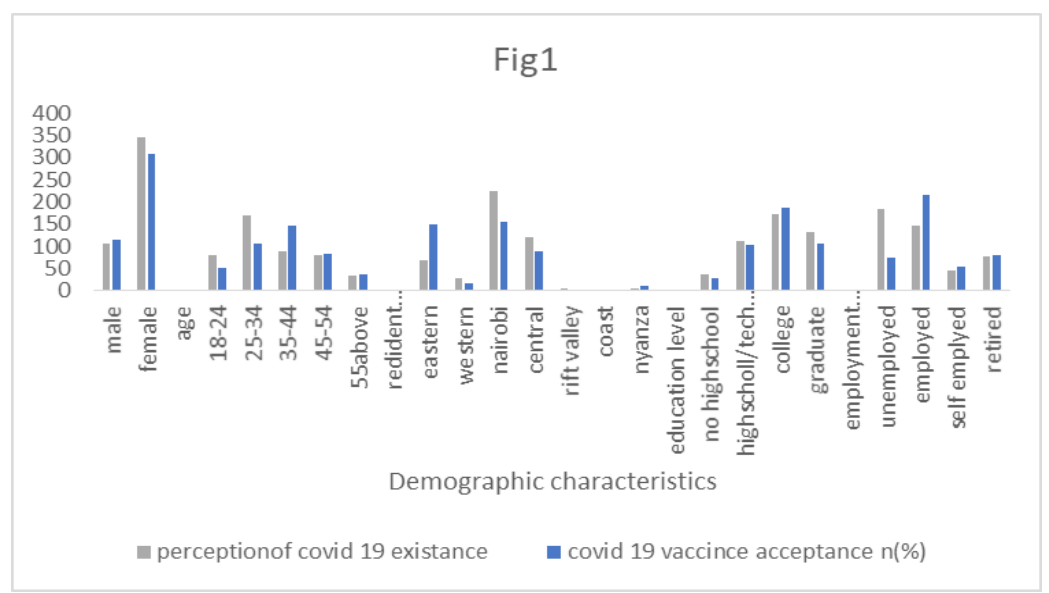

Fig 1; Comparison by demographic categories of number of participants who perceived the existence of Covid-19 to those who would accept the Covid-19 vaccine taken between January and $28^{\text {th }}$ February in Kenya. 


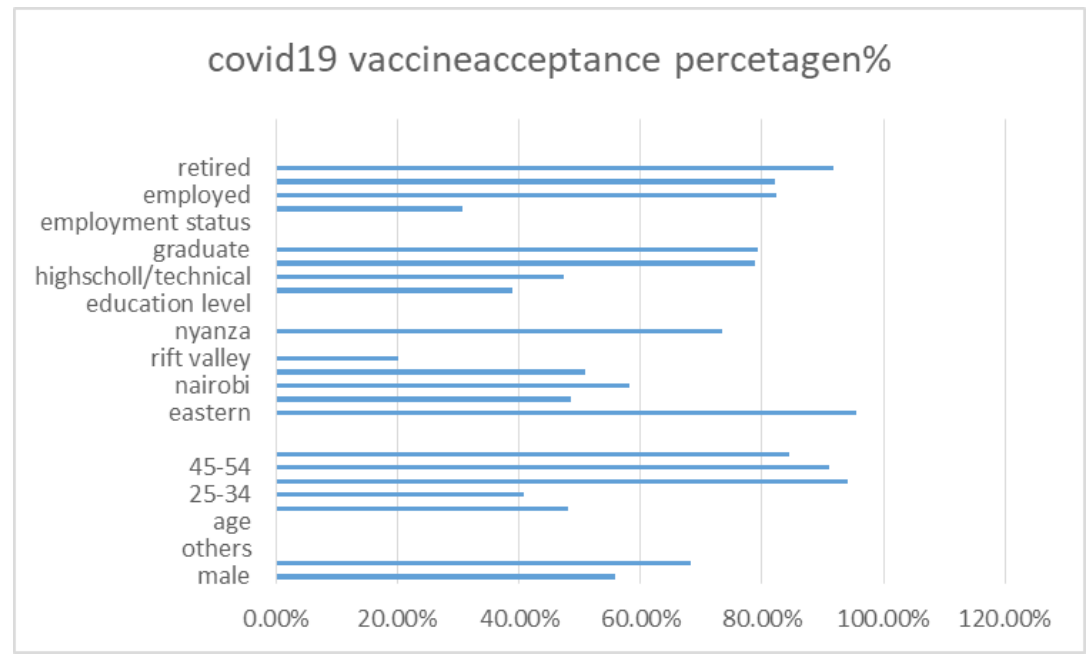

Fig 2; Comparison by demographic categories of percentage of participants who reported they would accept the Covid-19 vaccine in January and 28 ${ }^{\text {th }}$ February 2021.

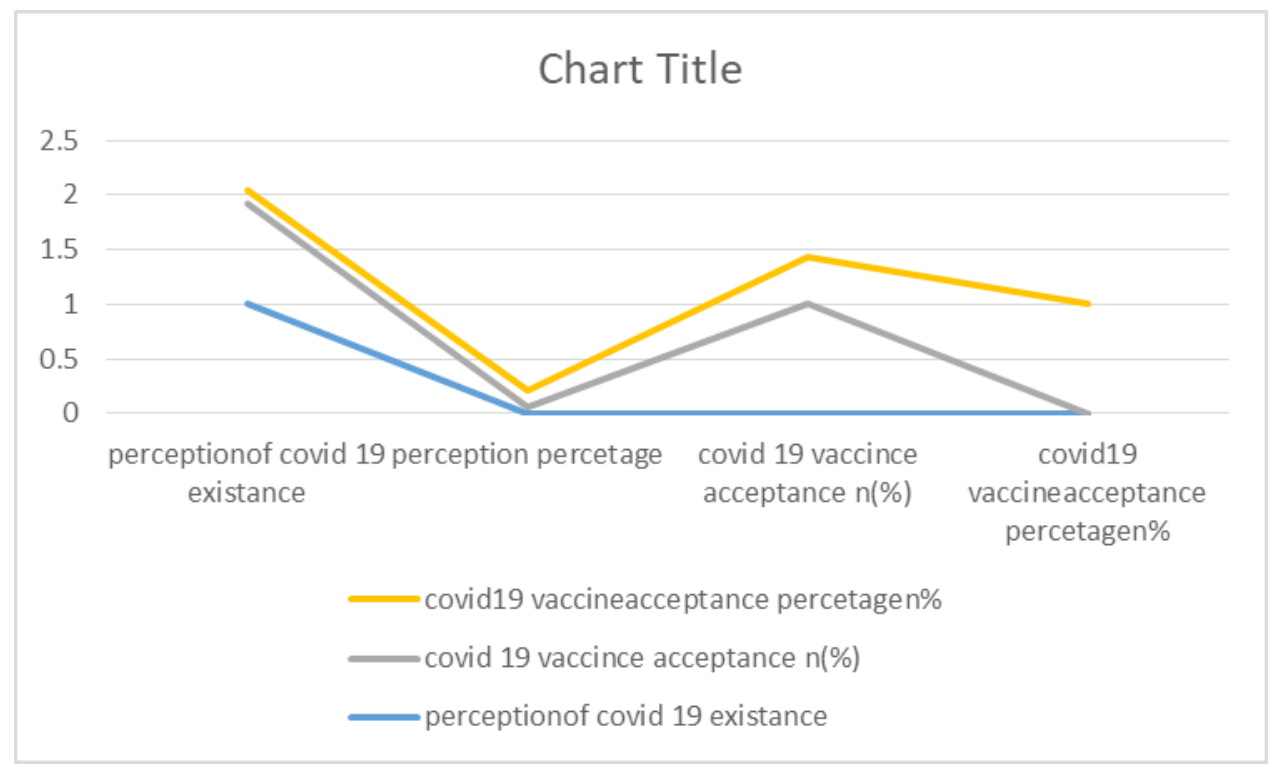

Figure 3; Correlation between Covid-19 perception and acceptance of the Covid-19 vaccine in the Kenyan population in January and February 2021 
